\title{
"NÃO EXISTE PECADO DO LADO DE BAIXO DO EQUADOR": POLÍTICAS DE CURRÍCULO, DIREITO À EDUCAÇÃO E AS ESCRITAS NUNCA ESCRITAS
}

\author{
"THERE IS NO SIN UNDER THE EQUATOR": curriculum policies, right to education \\ and unwritten writings
}

"NO HAY PECADO EN EL LADO DESDE ABAJO DEL ECUADOR": políticas curriculares, el derecho a la educación y las escritas no escritas

Maria Luiza Süssekind Professora Doutora da Universidade Federal do Estado do Rio de Janeiro (UNIRIO). Pós-Doutora em Currículo UBC/The University of British Columbia. luli551@hotmail.com

Raphael Pellegrini Mestrando do Programa de Pós-graduação em Educação da da Universidade Federal do Estado do Rio de Janeiro (UNIRIO). raphaelpellegrini@gmail.com

\begin{abstract}
RESUMO: Este ensaio apresenta desdobramentos e conclusões sobre a comunicação oral intitulada "BNCC E FORMAÇÃO DE PROFESSORXS: DESDOBRAMENTOS", que apresentamos no VII Encontro de Educadores/UFMA em que defendemos que currículos podem ser conversas complicadas de William F. Pinar, que, quase independentemente das disciplinas e planejamentos, versam sobre cosmopolitismos, historicidades, subjetividades, alegorias e silêncios. Argumentamos que a proposta de unificar currículos como forma de garantir o direito a aprendizagem (PNE/2014) prevê o controle dos processos de conhecer e do conhecimento produzido é uma negação a esse direito. Para isso, trazemos um debate derrideano sobre as noções de direito, decifrar e escrita como significados em disputa no campo das políticas curriculares contemporâneas e concluímos, acompanhados do pensamento ao Sul de Boaventura de Sousa Santos, que há escritas hegemônicas que decifram os significados de modo prescritivo, subalternizando e invalidando a alteridade e invisibilizando a condição de diferença e a inexorabilidade da criação - que entendemos condição ontológica da relação professorxs-estudantxs.
\end{abstract}

PALAVRAS-CHAVE: Currículo. Professores. Direito. escrita. Epistemologias do Sul.

ABSTRACT: This essay is based on the presentation entitled "BNCC AND TEACHER'S EDUCATION: DEVELOPMENTS" presented at the VII Meeting of Educators / UFMA in which we advocate that curricula can be understood as William F. Pinar's complicated conversations while considering cosmopolitanism, historicity, subjectivities, allegories and silence, almost independently of classes and planning. We argue that common core curricular policies as a way of guaranteeing the right to learning (PNE / 2014) foresees control of knowledge processes and of knowledge produced is a dedenial of this right. For this, we bring to a derridean debate the notions of rights, decipher and writing as disputed meanings in the field of contemporary curricular policies and conclude, accompanied by the South thinking ofBoaventura, that there are hegemonic writings that decipher meanings in a Prescriptive way subalternizing and invalidating alterity and erasing difference and the inexorability of creation - that we understand the ontological condition of the teacher-student-community relationship.

KEYWORDS: Curriculum. Teachers. Rights. Writing. Epistemologies of the South.

RESUMEN: Este ensayo presenta desdoblamientos y conclusiones sobre la comunicación oral intitulada "BNCC Y FORMACIÓN DE PROFESSORES: DESARROLLOS", que presentamos en el VII Encuentro de Educadores/UFMA en lo cual defendemos que currículos pueden ser conversas complejas de William F. Pinar, que, casi independientemente de las asignaturas y planeamientos, tratan sobre cosmopolitismos, historicidades, subjetividades, alegorías y silencios. Argumentamos que la propuesta de unificar el currículum con el fin de garantizar el derecho al aprendizaje (PNE/2014) prevé el control de los procesos de conocer y del conocimiento producido es una negación a este derecho. Por lo tanto, traemos un debate derrideano sobre las nociones de derecho, descifrar y escrita como significados en disputa en el campo de las políticas curriculares contemporáneas y concluimos, junto con el pensamiento desde el Sur de Boaventura de Sousa Santos, que hay escritas hegemónicas que descifran los significados de modo prescriptivo, subalternando e invalidando la alteridad e invisibilizando la condición de diferencia y la inexorabilidad de la creación - que entendemos condición ontológica de la relación profesorxs-estudiantxs.

PALABRAS CLAVE: Currículum. Profesorxs. Derecho. Escrita. Epistemologías del Sur.

Artigo recebido em setembro de 2016

Aprovado em novembro de 2016 


\title{
NÃO EXISTE PECADO | Maria Luiza Süssekind e Raphael Pellegrini
}

\begin{abstract}
Oh! Ai de mim! Tudo está claro! Ó luz, que eu te veja pela derradeira vez! Todos sabem: tudo me era interdito: ser filho de quem sou, casar-me com quem me casei... e... eu matei aquele a que eu não poderia matar!
\end{abstract}

Decifra-te a ti mesmo, Édipo! (SÓFOCLES, 1998, p. 59).

Decifrar a escrita nunca escrita.... Ao decifrar o enigma, Édipo não busca (ou encontra) nenhuma verdade universal, mas a si mesmo, sua biografia, como confirmarão os relatos de camponeses (FOUCAULT, 2013, p. 46). Artaud, escrevendo, reconhece que "só existe aquilo que escrevo" (DERRIDA, 2011, p. 249). As palavras que usamos escritas, lidas, conversadas multiplicam-se em significados, efeitos, dobras e desobediências, contrapõem-se a um esforço de decifração como busca de um significado único, verdadeiro e inconciliável com a perspectiva da diferença irredutível (DERRIDA, 2011, p. 425-426). As palavras são escrituras de diferença para Derrida. Também para professores, poetas, porque com elas nos mostram como se usa, abusa, lambuza ${ }^{1}$ sendo diferença. O decifrar, como um movimento para si, com o outro, multiplica sentidos, ou devora tudo.

Palavra soprada, que tenta carregar poemas do corpo, teatros de gestos, mas que, quando muito se afasta da experiência, é roubada. Caindo do corpo, aquela palavra "oferecendo-se em espetáculo" (DERRIDA, 2011, p. 258) para ser ouvida, recebida, "torna-se imediatamente palavra roubada" (Idem). Leis, políticas educacionais, livros didáticos, avaliações padronizadas e currículos unificados podem produzir as diferenças como inexistentes quando tomam palavras sopradas sob uma perspectiva de decifração prescritiva e uniformizadora, que busca silenciar e incapacitar a multiplicação de sentidos, as interpretações.

Espetaculares, essas palavras que se pronunciam aos sopros e, roubadas, acabam por se tornar indevidas, incorretas, impossíveis. Quando assim, as escritas que se querem centrais, como uma Base (BNCC) abduzem das escritas a vida, a experiência, sentindo "como um exilio a necessidade da interpretação" (DERRIDA, 2011, p. 425). Porque, nos jogos, nos signos, nas estruturas e na vida, "sem segurança" (Idem), afirmamos o "não-centro sem ser como perda do centro" (Idem). Advogamos pela impossibilidade da implantação de políticas educacionais do modo como são desenhadas (LOPES, 2015) quando entendemos professorxs ${ }^{2}$, estudantxs e comunidades escolares como pensantespraticantes ${ }^{3}$ dos cotidianos (OLIVEIRA, 2012), criativamente (CERTEAU, 1994), e, portanto, protagonistas das mesmas. Mergulhamos nos cotidianos e suas desobediências sem perder de vista o grande mapa, a estratégia (OLIVEIRA, 2012), os (des)centros.

Politicaspráticas (Idem) que produzem noções de currículo despidos de complexidade, como sendo um objeto, um documento, para assumir o papel de arma com um poder de educaçãodestruição em massa (SÜSSEKIND, 2014a). Este poder devotado a um documento sugere não só uma perspectiva da produção de sentidos do mundo como também uma permanente decifração que busca uma linguagem pura e única, como subestima toda e qualquer interação social e, portanto, consequente negociação de sentidos que envolve os usos dos praticantes dos cotidianos (CERTEAU, 1994). Abduz a difference das palavras sopradas. Acreditando no poder do conhecimento curricularmente planejável e ensinável que decifra e se pensa capaz de modelar o mundo,

\footnotetext{
${ }^{1}$ Não Existe Pecado Ao Sul do Equador. Compositor: Chico Buarque - Ruy Guerra. 1972 @ by Cara Nova Editora Musical Ltda.

${ }^{2}$ Escolhemos empregar o X no lugar do marcador de gênero binário masculino/feminino como forma de reforçar o compromisso políticoepistemológico da pesquisa com as políticas de diferença.

${ }^{3}$ Inserida no campo das pesquisas nosdoscom os cotidianos, a presente pesquisa emprega em muitos momentos a justaposição, escrita e estetização diferenciada de palavras afim de buscar reinventar as palavras já que a língua[gem] prescrita não alcança acessos aos sentidos do vivido.
} 


\section{A DIVERSIDADE NAS POLÍTICAS EDUCACIONAIS NO BRASIL | Paulo Gomes Lima}

a "pretensão dos produtores de informar uma população, dar forma as práticas sociais" (CERTEAU, 1994, p. 260) divide a sociedade, as escolas, os currículos, o trabalho docente e as práticas de conhecer de modo abissal - jogando para o abismo conhecimentos considerados in-válidos. Tupi, or not tupi that is the question. (ANDRADE, 1928).

Esse modo de pensar o mundo, o conhecimento e as políticas que chamamos com Santos de abissal (2010), pois aloca do lado de lá da linha o que não tem valor, pode ser aproximado do que é entendido por Pinar (2009) como um aprender mal de si mesmo e do outro. O abissal, entretanto, surpreende-se com as resistências, as astúcias, as re-existências e coexistências (SANTOS, 2008, p. 14) (SUSSEKIND; PELLEGRII, 2016) na vida, na culinária (GIARD, 1994) e das escolas (OLIVEIRA, 2012). Conhecer, ensinar, pesquisar, escrever, conversar com e para diferença desmonta a falácia da harmonia, do consenso, da categoria que produz a organização e a previsibilidade das consequências. Reverte a estrutura ao simulacro, o conceito à decifração e se desdobra no acontecimento, como um escape. Democracias, currículos, conhecimentos, pesquisas são, assim, pensados como teatros de ações, bricolagens, comunidades de dissenso (PINAR, 2012, p. 196). Quando dialogam não hierarquicamente os conhecimentos em dissenso podem colaborar entre si, numa tessitura de interconhecimentos, ecologicamente (SANTOS, 2003). Quando não, produzem mesmidade e abissalidade, des-reconhecem o outro em sua alteridade e legitimidade, se tornam epistemicidas (SANTOS, 2003).

Não só os colonizadores e seus descendentes compreenderam mal o Outro. Os colonizados e seus descendentes, como Frantz Fanon predisse, apreenderam mal a si mesmos (PINAR, 2009, p. 150)

[...] fantasias progressistas que concebem a escola como laboratório de democracia (PINAR, 2008, p. 141)

Este ensaio apresenta desdobramentos e conclusões sobre a comunicação oral intitulada "BNCC E FORMAÇÃO DE PROFESSORXS: DESDOBRAMENTOS" que apresentamos no VII Encontro de Educadores/UFMA em que defendemos que currículos podem ser conversas complicadas de William F. Pinar, que, quase independentemente das disciplinas e planejamentos, versam sobre cosmopolitismos, historicidades, subjetividades, alegorias e silêncios. Argumentamos que a proposta de unificar currículos como forma de garantir o direito a aprendizagem (PNE/2014), por meio de objetivos de aprendizagem assumidos como degraus a serem vencidos, elencados numa Base, prevê o controle dos processos de conhecer e do conhecimento produzido é uma negação a esse direito. Para isso, trazemos um debate derrideano sobre as noções de direito, decifrar e escrita como significados em disputa no campo das políticas curriculares contemporâneas e concluímos, acompanhados do pensamento ao Sul de Boaventura de Sousa Santos, que há escritas hegemônicas que decifram os significados de modo prescritivo, subalternizando e invalidando a alteridade e invisibilizando a condição de diferença e a inexorabilidade da criação - que entendemos condição ontológica da relação professorxs-estudantxs.

"Vamos fazer um pecado safado debaixo do meu cobertor"4

\footnotetext{
${ }^{1}$ Não Existe Pecado Ao Sul do Equador. Compositor: Chico Buarque - Ruy Guerra. 1972 @ by Cara Nova Editora Musical Ltda. Este verso foi censurado pela ditadura militar que também primava pelo controle das palavras e seus significados. Assim, o verso foi censurado e as palavras foram substituídas por "vamos fazer um pecado rasgado, suado, a todo vapor". Atualmente, dado o nomadismo das palavras (LEVY, 1996, p. 39) pecar sob o cobertor não tem sido alvo de censura, ao menos em programas na TV como Big Brother.
} 
NÃO EXISTE PECADO | Maria Luiza Süssekind e Raphael Pellegrini

\begin{abstract}
Deste modo o relevo e o desenho das estruturas tornam-se mais visíveis quando o conteúdo, que é a energia viva do sentido, encontra-se neutralizado. Um pouco como a arquitetura de uma cidade desabitada ou destruída, reduzida ao esqueleto por uma catástrofe da natureza ou da arte. Cidade não mais habitada mas também não simplesmente abandonada; antes assombrada pelo sentido e pela cultura. Este assombramento que a impede aqui de volta a ser natureza é talvez em geral o modo de presença ou de ausência da própria coisa na linguagem pura. Linguagem pura que gostaria de abrigar a literatura pura, objeto da crítica literária pura. (DERRIDA, 2011, p.5)

A generosidade da inspiração, a irrupção positiva de uma palavra que vem não sei donde, acerca da qual sei, se for Antonin Artaud, que não sei donde vem nem quem fala, essa fecundidade do outro sopro é o impoder: não a ausência, mas a irresponsabilidade radical da palavra, a irresponsabilidade como poder e origem da palavra. (DERRIDA, 2011, p.259) Claire Parnet ${ }^{5}$ : Preparar muito significava quanto tempo de preparação?

Gilles Deleuze: Tenho de refletir. Como tudo, são ensaios. Uma aula é ensaiada. É como no teatro e nas cançonetas, há ensaios. Se não tivermos ensaiado o bastante, não estaremos inspirados. Uma aula quer dizer momentos de inspiração, senão não quer dizer nada. (DELEUZE; PARNET; 1994)
\end{abstract}

Ao se esforçarem por produzir inexistências com conhecimentos tecidos relacionamente entre os sujeitos praticantes dos cotidianos das salas de aula, o pensamento abissal em geral e, em foco, as políticas de unificação curricular em voga globalmente - e consequentemente o emprego de avaliações externas padronizadas, como o $\mathrm{PISA}^{6}$ - abissalizam a condição ontológica de produção de saberes que se dá num permanente jogo do impoder (DERRIDA, 2011, p. 251). Distante de uma impotência, assumir que a produção de saberes se faz sem controle e sem destino, é reabitar as cidades em suas complexidades.

Nada pode ser mais contrário à imprevisibilidade dos encontros cotidianos do que um currículo que busca a padronização e organização daquilo que ainda não aconteceu e o faz com o intuito de (in)validar certos sentidos em detrimento de outros por meio das avaliações. Produzir um currículo que não é currículo, mas sim papel, lista, prescrição de significados, é propor aos professorxs que negociem com seus estudantes a criação de conhecimentos a partir de uma codificação arbitrária de significados cobrados em testagens externas padronizadas. A escrita nunca escrita que deve ser decifrada no currículo como Base é um currículo de previsibilidade, prescrição e controle de significados, sem vínculo com os currículos dos pensadospraticados nos cotidianos (OLIVEIRA, 2012, p. 11) pelos múltiplos sujeitos das escolas.

Por mais prescritivo que seja o documento curricular, e a Base projeta altíssimo nível de prescrição, controle das aprendizagens dos estudantxs e responsabilização dos professorxs por es-ses resultados, pensamos que, nas conversas complicadas que são os currículos, os conheci- mentos, os documentos curriculares trazem escritas sobrepostas, reutilizadas. Escritas com o caos

\footnotetext{
${ }^{5}$ Trecho retirado da transcrição da entrevista em vídeo com Gilles Deleuze realizada por Claire Parnet em 1988, publicizada somente nos anos de 1994 e 1995 já próximo a morte do filósofo. Inicialmente o acordo entre Deleuze e a documentarista seria de publicação somente após a sua morte, porém com a saúde agravada, o filósofo consentiu sua divulgação ainda em vida.

${ }^{6}$ O PISA é uma avaliação externa produzida pela OCDE - Organização para a Cooperação e Desenvolvimento Econômico -, aplicada em 65 países com o intuito de atribuir graus de desenvolvimento econômico em função do resultado da avaliação externa com base no desempenho de estudantes. Como consta no site do Ministério da Educação: "O objetivo do Pisa é produzir indicadores que contribuam para a discussão da qualidade da educação nos países participantes, de modo a subsidiar políticas de melhoria do ensino básico. A avaliação procura verificar até que ponto as escolas de cada país participante estão preparando seus jovens para exercer o papel de cidadãos na sociedade contemporânea. " (BRASIL, 2016a)
} 


\title{
NÃO EXISTE PECADO | Maria Luiza Süssekind e Raphael Pellegrini
}

que não nos permitem a decifração sem que para isso retiremos tudo que nos chega sem aviso, tudo que seja da ordem do acontecimento.

\begin{abstract}
Uma base comum curricular, documento de caráter normativo, é referência para que as escolas e os sistemas de ensino elaborem seus currículos, constituindo-se instrumento de gestão pedagógica das redes. Para tal, precisa estar articulada a um conjunto de outras políticas e ações, em âmbito federal, estadual e municipal, que permitam a efetivação de princípios, metas e objetivos em torno dos quais se organiza. (BRASIL, 2016b, p. 25)

Ora o caos é um imenso buraco negro, e nos esforçamos para fixar nele um ponto frágil como centro. Ora organizamos em torno do ponto uma "pose" (mais do que uma forma) calma e estável: o buraco negro deveio um em-casa. Ora enxertamos uma escapada nessa pose, para fora do buraco negro. (DELEUZE; GUATTARI, 2012, p. 123)
\end{abstract}

A sala de aula pode assim ser pensada como um caos. Um corpo sem órgãos (DELUZE; GUATTARI, 2011) com seus estratos e platôs, seus agenciamentos, movimentos, fluxos. Estratificações e desestratificações. A sala de aula pode ser percorrida, ocupada por estudantesprofessores que dialogam nesse caos onde o eu é muitos outros o tempo todo e onde esses outros não cessam de se fazer e desfazer. Nesse sentido, o currículo também se faz no caos que acontece no encontro entre diferentes e produz ordens e escritas imprevisíveis porque relacionais, situacionais, glocais. O currículo é localidade, cidade, roteiro, mas é desterritorialização, deslocamento e perambulação. Faz parte do caos do ônibus, da rua, do sinal de trânsito, do noticiário do jornal. Não se trata de opor esses outros espaços à sala de aula, pelo contrário, eles se enredam todo o tempo, se movem juntos mesmo quando um aparenta ser mais predominante que o outro. Não há lógica fixa que possa determinar a força com que um meio faz sobre o outro. Jogo dinâmico próprio do caos. "Virtualizante, a escrita dessincroniza e deslocaliza". (LEVY, 1996, p. 38)

É a partir dessa proposta de caos, complexidade, deslocamento e diferença que podemos produzir sentidos com o trabalho docente e os currículos nos cotidianos escolares (e suas narrativas e escritas) nunca a partir de uma ideia de realidade preexistente nem de distanciamento ou fixidez, já que somos fios dessas redes, mas sim num permanente jogo de sentidos negociados com os sujeitos que praticam os cotidianos. Ao se perguntar se e como é possível "transmitir" o que foi sendo apreendido/aprendido, Alves desdobra o problema:

É preciso uma outra escrita para além da já aprendida. Há assim, uma outra escritura a aprender: aquela que talvez se expresse como múltiplas linguagens (de sons, de imagens, de toques, de cheiros etc.) e que, talvez, não possa ser chamada mais de "escrita"; que não obedeça à linearidade de exposição, mas que teça, ao ser feita, uma rede de múltiplos, diferentes e diversos fios; que pergunte muito além de dar respostas; que duvide do próprio ato de afirmar, que diga e desdiga... (ALVES, 2008, p. 30-31)

Numa escrita já aprendida, a ideia de uma Base traz a decifração prescritiva do resultado do conhecer. Há essa escrita já aprendida, que nunca foi escrita porque não se recheia de experiência, desfaz do vivido. Desvaloriza o oral em nome de uma economia escriturística da palavra. Escrita que busca fazer uma aula que seja entendida do modo igual pelos diferentes. Uma aula para ser avaliada a posteriori como diagnóstico de sucesso ou fracasso de estudantes e professores. A unificação curricular produz a linearidade por meio da relação direta entre causa e efeito, esmagando todas as outras possibilidades de temporalidades e espacialidades do conhecer. Considerar esse pensamento soa de máxima importância para nós no momento em que a mordaças, projetos legislativos e políticas oficiais caçam palavras, temas e disciplinas expurgando as diferenças dos espaços escolares. 
Currículo planificado que não se permite ser matéria vida, poesia, música, movimento, mas sim planejamento centralizante, estrutural, com pontos de entrada e saída pré-definidos sem abrir espaço para que professorxs, estudantxs e comunidades possam definir o que lhes convém aprender juntos, em suas historicidades e glocalidades, negociando seus projetos político-pedagógicos como sonhou, num esforço de democracia e localidade a Lei de 1996 (LDB/1996). Como alinha e foge Deleuze, "Numa aula, cada grupo ou cada estudante pega o que lhe convém. Uma aula ruim é a que não convém a ninguém. Não podemos dizer que tudo convém a todos." (DELEUZE; PARNET, 1994) E por isso, torna-se difícil conceber uma aula que interesse a todxs e seja completamente entendida.

O que é para todos é para ninguém. Homogeneíza-se sujeitos, currículos e avaliações a fim de apagar a condição ontológica dos seres humanos de produzir diferença. Do Sul, no jogo de palavras do rap, desloca e desdobra, como nos diz Oeste,

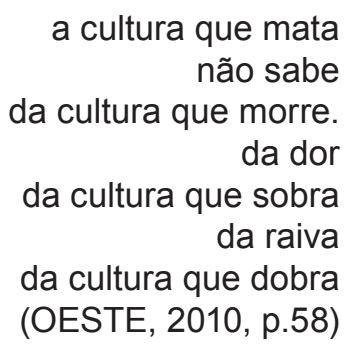

Deslocando-se, Derrida, ao ler Artaud, apresenta-nos a uma palavra soprada longe do corpo que, furtada por aquele que comenta e produz um exemplo, parece "alinhar numa ordem, ordem da verdade essencial ou de uma estrutura real”. (DERRIDA, 2011, p. 257-258) Levados a sério, a crítica, a pesquisa, o ensino, quando soprados funcionam da mesma maneira: fazem um exemplo. Quando isso acontece, "o meio toma o lugar da mensagem" (CERTEAU, 1994, p. 261).

\begin{abstract}
Toda palavra caída do corpo, oferecendo-se para ser ouvida ou recebida, oferecendo-se em espetáculo torna-se imediatamente uma palavra roubada. Significação de que sou despojado porque ela é significação" (DERRIDA, 2011, p. 257-258.)

Tal é o trabalho da leitura: a partir de uma linearidade ou uma platitude inicial, esse ato de rasgar, de amarrotar, de torcer, de recosturar o texto para abrir um meio vivo no qual possa desdobrar o sentido. (LEVY, 1996, p. 36)
\end{abstract}

Palavras escritas e faladas, sopradas para longe dos protagonistas dos currículos, palavras que julgam por meio dos processos avaliativos padronizados e abissalizam as possibilidades de ser, cristalizando as diferenças e hierarquizando os modos possíveis de conhecer. Assim, se tecem caminhos privilegiados únicos do conhecer, que colados ao julgamento externo àquele que conhece, marcam os territórios possíveis para os sujeitos dos cotidianos escolares percorrem. Linhas abissais móveis que, pelo exemplo, ordem, causalidade, apagam sujeitos e modos de viver com o mundo, jogando no abismo do Sul, do local, do gênero, do fracasso estudantxs e professorxs em suas redes de conhecimentos e subjetividades, historicidades. Contudo, sabemos, "ler é uma operação de caça" (CERTEAU, 1994, p. 259).

Quando é lição de esculacho, olha aí, sai de baixo, eu sou professor ${ }^{7}$.

\footnotetext{
${ }^{7}$ Não Existe Pecado Ao Sul do Equador. Compositor: Chico Buarque - Ruy Guerra. 1972 @ by Cara Nova Editora Musical Ltda.
} 


\title{
NÃO EXISTE PECADO | Maria Luiza Süssekind e Raphael Pellegrini
}

Já argumentamos que professorxs e estudantxs são tornados ruins quando exigimos que produzam resultados iguais (PINAR; 2008; SÜSSEKIND; 2014), pois "é impossível encontrar duas escolas iguais" (EZPELETA; ROCKWELL;1989, p. 58), sendo assim desvalorizados, demonizados, esculachados em pesquisas, na mídia e pela sociedade em geral. Nesse sentido, as (im)possibilidades (ontológica; epistemológica) dos professores de darem as mesmas aulas, seguirem manuais ou treinarem seus estudantxs para darem respostas padronizadas são percebidas como (in)capacidade ou (des)preparo (SÜSSEKIND, 2014a). Ressaltando a ideia de que professores precisam ser "formados" antes mesmos de serem ouvidos, Pinar (SÜSSEKIND; PINAR, 2014) reforça o papel dos testes padronizados na demonização de professorxs e estudantxs ao afirmar:

\begin{abstract}
Na verdade, se todos tivessem um desempenho perfeito nos testes, os testes seriam inúteis, certo? Então os testes somente têm sentido quando selecionam e distinguem as pessoas, portanto, é preciso que haja falhas e fracassos. Alguém precisa perder. Então é uma corrida numa esteira que não só nunca é desligada, como a velocidade só aumenta. [...] A experiência do teste substitui a experiência acadêmica de compreensão. (SÜSSEKIND; PINAR, 2014, p. 94-95)

Comparada com instrumentos curriculares anteriores, a proposta da BNCC para o ensino de Filosofia mostra-se mais propositiva que a dos PCNEM (2000 e 2002), (...) O êxito da proposta, de sua conversão em currículos e implementação nas escolas, depende, naturalmente, da concomitante valorização e investimento em formação de professores de Filosofia, de todo presentes entre as metas do PNE (Lei 13005/2014). (BRASIL, 2016b, p. 636)
\end{abstract}

Nosso investimento politicoepistemológico no re-conhecimento do trabalho docente como criação intelectual reside também na "refutação das teses comuns sobre a passividade dos consumidores, e a massificação dos comportamentos" (GIARD, 1994, p. 27) nos impõe a pensar os conhecimentos sempre no plural, considerando sua fabricação cotidiana e suas incontáveis possibilidades de usos (CERTEAU, 1994). A atividade silenciosa que é a leitura "parece aliás constituir o ponto máximo da passividade que caracterizaria o consumidor" (CERTEAU, 1994, p. 49) no contexto escriturístico em que o oral "não contribui para o progresso" (CERTEAU, 1994, p. 224) e que, nos três últimos séculos, vincula à iniciação na sociedade capitalista à pratica da escrita, sendo preciso "sentir os efeitos inquietantes de um tão prodigioso avanço para que suspeitássemos ser a formação da criança moderna uma pratica escriturística” (CERTEAU, 1994, p. 227). Mas Certeau (1994) adverte que o leitor será sempre impertinente, escrevendo e inscrevendo outros textos com suas leituras, pois

onde o aparelho cientifico (o nosso) é levado a partilhar a ilusão dos poderes de que é necessariamente solidário, isto é, supor as multidões transformadas pelas conquistas e vitorias de uma produção expansionista, é sempre bom recordar que não se deve tomar os outros por idiotas. (CERTEAU, 1994, p. 273).

Decifrando, explicando, significando e interpretando, o pensamento abissal (SANTOS, 2011), expressão incestuosa do paradigma cientifico hegemônico, cria simulacros com seus pensamentos, que se assumem realidade (DERRIDA, 2011, p.40) e ofuscam o ordinário (CERTEAU, 1994). Máquinas conceituais barulhentas que tentam, pela explicação que faz exemplo de entendimento de verdade, nos ensurdecer para os sussurros dos praticantes. Produções impertinentes que não cessam de acontecer que se fazem ativamente. Palavras segundas que se metamorfoseiam em terceiras, quartas, quintas. Produções astutas dos homens ordinários que bricolam no impoder suas possibilidades de ser. Territorializações e desterritorializações para o imprevisível que é bricolado com o outro a cada instante, na relação que produz sempre diferença. Currículos são cidades, são textos que se multiplicam no jogo de sentidos emudecidas pelas máquinas de surdez da ordem 


\section{NÃO EXISTE PECADO | Maria Luiza Süssekind e Raphael Pellegrini}

capitalista, ocidental, masculina, branca e do Norte. O Sul não é a priori desobediente, a percepção da desobediência é sua palavra, sua escrita, sua diferença, sua existência.

Nunca fomos catequizados. Fizemos foi Carnaval. (ANDRADE, 1928), ou seja, parece ser hora de aprendermos a considerar o papel dos homens ordinários nessa bricolagem que é o mundo social, entre palavras decifradas, de-cifradas, lidas, escritas, prescritas, roubadas e inventadas. Aqueles que, nas artes do fraco: "inventa[m] nos textos outra coisa que não aquilo que era a "intenção" deles. (...) Combina os seus fragmentos e cria algo não-sabido no espaço organizado por sua capacidade de permitir uma pluralidade indefinida de significações". (CERTEAU, 1994, p. 265)

Diferente das práticas escriturísticas são as artes de conversar. Conversas permitem "práticas transformadoras de situações de palavra, de produções verbais onde o entrelaçamento das posições locutoras instaura um tecido oral sem proprietários individuais" (CERTEAU, 1994, p. 50) e, como em platôs, vão se bricolando, inventando, subvertendo e criando cotidianamente conhecimentos e subjetividades. Currículos são conversa complicadas, bricolagens que vão de-cifrando pergaminhos em que

Cor é palavra

Corpo é palavra

Trança é palavra.

(OESTE, 2010, p. 58)

Percorrer as conversas é, nesse sentido, des-cobrir e inventar maneiras de conhecer que re-conhecem nos cotidianos a presença de multidões que se encontram e jogam permanentemente com sentidos, produzindo interações e conhecimentos em suas inter-relações. Caminhos tortos, atalhos, deslocamentos, acontecimentos que trazem o fugaz, o fugidio, as artes do fraco. As conversas não cabem nas estruturas, são como "os jogos dos passos moldam espaços, tecem lugares" (CERTEAU, 1994, p. 176), são "retóricas ambulantes" combinando usos, estilos e lugares na linguagem ordinária (CERTEAU, 1994, p. 179).

É nesse sentido que parece oportuno que utilizemos os versos de Oeste (2010) e o pensamento ao Sul de Santos (2010) para pensar algumas das disputas que se fazem presentes nas políticas educacionais da atualidade quando entendemos as salas de aula, as escolas e os currículos como conversas complicadas. Conversas complicadas não cabem em manuais e provas que usam palavras roubadas e aprisionam as escritas autorais e vivas. Que projeto de mundo, de educação, de aprendizagem, de currículo habita a Base e suas ações coordenadas?

Alternativamente, pensar essas políticas não como consenso, mas como negociações que convocam comunidades sem consenso (MILLER, 2010, p.96) é um exercício politicoepistemológico que nos move a assumir a prática de conhecer como dissenso (PINAR; MILLER, 2014). Assim, pensar as políticas e os conhecimentos como sendo criados no desacordo, e não como uma fantasia de harmonia (MILLER, 2010) e progresso, desafia não só qualquer pretensão de "pureza" ou "intencionalidade" de seus textos, mas coloca em cheque a ideia de Base e sua prescrição sobre os resultados do conhecer. Por outro lado, a possibilidade de uma base curricular que se apoie em políticas atravessadas por algum tipo de crença poderosa (SÜSSEKIND, 2014) capaz de prever as conversas complicadas de cada uma das salas de aula das mais de 203 mil escolas do Brasil toca a ação de decifrar, como previsão, ou construir ficcionalmente, uma realidade nunca escrita porque impossível de ser vivenciada, e portanto, DESumanizada. É nessa perspectiva que o barulho das fortes vozes reformistas silenciam os caminhos ao Sul dos currículos.

Chamamos, assim, de reformismo a ideia que perpassa diversos países como uma tendência de reforma com tendência a ver de modo antiquado, tecnicista e estrutural o currículo. Mais controlador que o Currículos Mínimos da Ditadura, o reformismo atrela a unificação curricular - sob a egide da 
NÃO EXISTE PECADO | Maria Luiza Süssekind e Raphael Pellegrini

escola como lugar de treinamento para o mercado de trabalho globalizado - à produção de um documento curricular nacional e às testagens padronizadas de controle de resultados que, em geral, são produzidos por equipes de especialistas (com maior ou menor grau de discussão com a sociedade).

Produz-se assim uma divisão entre "planejadores" e "executores", estabelecida hierarquicamente e reforçada politicamente, teórica e epistemologicamente por uma base curricular que não corresponde ao projeto de educação e nação democráticos e plurais que pensamos e que está refletido em nossa legislação (ANPED, 2015, p.6).

Tal projeto unificador não respeita a diferença, a autonomia e não fomenta as práticas de democracia nos espaçostempos educativos, além de desvalorizar os saberes dos professorxs e, sobretudo, desconsiderar e silenciar os saberes endógenos locais.

Nesse sentido, é necessário marcar que tal movimento se orienta por uma concepção de formação voltada para o mercado de trabalho. Não se busca formar a partir dos valores da sociedade e do trabalho como está definido na LDB (1996), mas sim para o cumprimento das exigências sempre flutuantes do mercado de trabalho. Aquilo que os mercados demandarem é o que precisará ser feito na escola. Nesse sentido, tudo aquilo que é considerado como conhecimento válido pelas políticas oficiais está fora da escola. Quem produz o currículo está fora da escola. Quem modela e analisa as avaliações também está fora da escola. Quem planeja o treinamento de professores e faz o livro didático também estão fora da escola. Ou seja, todo o trabalho cotidiano realizado nos espaçostempos escolares é considerado inexistente dentro desse modelo de política educacional e curricular. Des-valorização, des-caracterização, DESumanização do trabalho docente. Palavras conversadas nos cotidianos pelas comunidades educativas que são roubadas, e tornadas piores, invisíveis ou inexistentes.

Mesmo com a máquina voltada para o mercado, força políticaeconômica de seu forte ruído, se apoia diretamente numa afirmativa dificilmente contestável: a do direito à educação para todos. Direito, garantido por lei, e usufruído de modo no qual a "escrita nunca escrita" é utilizada como blindagem dos interesses de grandes corporações dos setores econômicos e industriais no que tange à (des)qualificação de mão-de-obra e à produção e venda de materiais didáticos, testes padronizados e projetos de treinamento-formação com base nos resultados (não) obtidos nas testagens.

Currículos prescritos porque não vividos apagam outras escritas, silenciam outras vozes, fixam os significados (LOPES, 2015, p.456), mas não param o mundo. Ameaçam a diversidade como valor social (ANPED, 2015, p. 1), mas não anulam a diferença, pois, em nome de outras escritas, de-cifrando a si mesmos, xs estudantxs ocupam as escolas e gritam que a escola é deles. Gritam em outras práticas de mundovida que assustam a mídia e os governantes com suas palavrascorpos-sem-órgãos.

Figura 1. Ocupação Ensino Médio RJ, abril/2016.

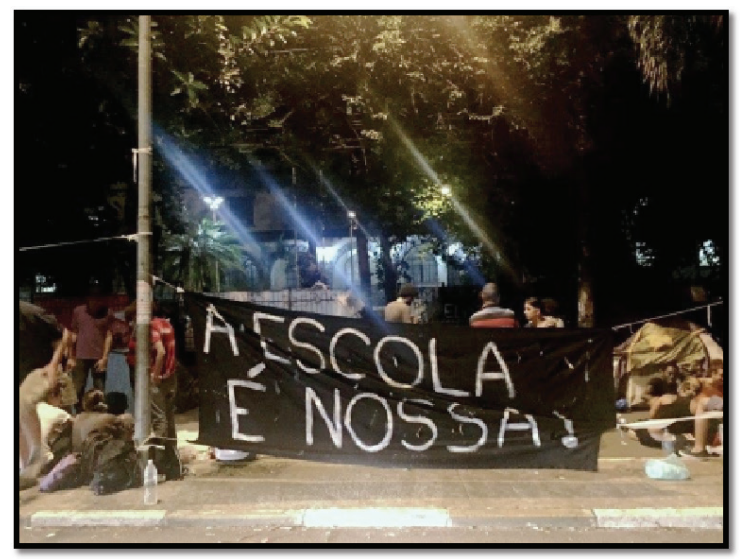

Fonte: Mídia Ninja. 


\section{NÃO EXISTE PECADO | Maria Luiza Süssekind e Raphael Pellegrini}

Nas ocupações, nas des-obediências das práticas com currículos produzimos impoder. Currículos de im-poder, antropofágicos, ao Sul, que jogam de formas infinitas com um conjunto de peças finitas, a totalização e planificação são sempre impossíveis.

\footnotetext{
Se a totalização não tem mais sentido, não é porque a infinidade de um campo não pode ser coberta por um olhar ou um discurso finitos, mas porque a natureza do campo - a saber a linguagem e uma linguagem infinita - exclui a totalização: este campo é com efeito o de um jogo, isto é, de substituições infinitas no fechamento e um conjunto finito. (DERRIDA, 2011, p.421)
}

Nesse embate, entre uma proposta unificadora e a impossibilidade de controle da criação cotidiana, que, a partir da discussão de Boaventura de Sousa Santos (2013) acerca dos direitos humanos, buscamos nos aproximar das ideias que tocam o direito à educação. Assim, principalmente a partir de sua afirmação de que "a grande maioria da população mundial não é sujeito de direitos humanos. É objecto de discursos [de direitos humanos]" (SANTOS, 2013, p. 2), buscamos pensar o direito à educação, entendendo que a implementação de uma Base se utiliza de tal determinação (in)contestável para projetar um futuro a partir da violação de sua própria premissa, tornando a maioria dos sujeitos das escolas objetos dos discursos de direito à educação e não os assumindo como sujeitos de direito à educação. (SÜSSEKIND; PELLEGRINI, 2016).

Assim, advogando que a ideia de implementação de uma base desloca não apenas os (des) acordos de sentidos daquilo que temos assumido como currículo, formação inicial e continuada de professorxs, trabalho docente e avaliação, acreditamos ser necessário puxar outros fios que permitam produzir entendimentos diversos sobre o direito à educação daquele proposto pelos defensores da Base, já que esse, calcado numa razão indolente, subalterniza tudo que não cabe em suas categorias ou competências, tornando inexistente múltiplos saberes, escritas e astúcias produzidas cotidianamente nas salas de aula da educação básica ou superior. Nesse sentido, a crença no poder de previsão do futuro a partir da potência do conhecimento indolente leva tais políticas a projetar uma reformar educacional (currículos, avaliações, formação docente, direção...) antes mesmo de ser capaz de escutar as vozes dos praticantes que narram aquilo que acontece todos os dias nesses espaçostempos.

Denunciamos que tais políticas de unificação curricular e testagens em larga escala possuem o apoio de representantes dos setores industrial e financeiro brasileiros e estrangeiros (MACEDO, 2015) - interessados, talvez, nos altos lucros que a venda de materiais, testes e programas (eternos) de qualificação de professorxs podem oportunizar, entendendo assim que escolas (des) preparariam eficientemente a massa de estudantes para serem convertidos em trabalhadores (in) competentes - e que mimetizam as políticas já implantadas, sem sucesso (PINAR, 2008; PRICE, 2014; EDLING, 2014), em outros países.

Programas que DESqualificam em seus treinamentos a condição de intelectual (MOREIRA, 1995) do trabalho de professorxs. Se de certo modo cabem no vocabulário do mercado, ao contrário, por exemplo, das ideias de diferença/diversidade e Sul, as ideias como eficiência e competência têm dado pouquíssima contribuição para o campo da educação, apesar de historicamente presentes na relação escola-sociedade-mercado (PARASKEVA, 2011). Mas, seja na formação de professorxs ou nas práticas educativas, exatamente por remeterem a esse escriturismo, essa (im)possibilidade de decifrar e de escrever a palavra nunca escrita quando sabemos que "todo conhecimento é autoconhecimento" (SANTOS, 2008, p.80). (SÜSSEKIND; PELLEGRINI, 2016) multiplicam as impossibilidades e inexistências. 


\title{
NÃO EXISTE PECADO | Maria Luiza Süssekind e Raphael Pellegrini
}

\begin{abstract}
Para que possa cumprir este papel, ao longo da educação básica serão mobilizados recursos de todas as áreas de conhecimento e de cada um de seus componentes curriculares, de forma articulada e progressiva..." (BRASIL, 2015b, pg.8; grifo do autor).
\end{abstract}

As crianças, adolescentes, jovens e adultos, sujeitos da Educação Básica, têm direito: ao respeito e ao acolhimento na sua diversidade, sem preconceitos de origem, etnia, gênero, orientação sexual, idade, convicção religiosa ou quaisquer outras formas de discriminação, bem como terem valorizados seus saberes, identidades, culturas e potencialidades, reconhecendo-se como parte de uma coletividade com a qual devem se comprometer; à apropriação de conhecimentos referentes à área socioambiental que afetam a vida e a dignidade humanas em âmbito local, regional e global, de modo que possam assumir posicionamentos ético em relação ao cuidado de si mesmo, dos outros e do planeta. (BRASIL, 2016b, p.34)

Só a Antropofagia nos une. Socialmente. Economicamente. Filosoficamente. Única lei do mundo. Expressão mascarada de todos os individualismos, de todos os coletivismos. De todas as religiões. De todos os tratados de paz. (ANDRADE, 1928, p. 1).

Ao ser ancorada na afirmação politicamente (in)contestável de que todo cidadão tem o direito à educação e, portanto, na atual compreensão a uma Base, a BNCC, quando tomada em sua perspectiva epistemológica, a qual inferimos ser calcada na primazia do pensamento científico do Norte, traz consigo caminhos privilegiados únicos de conhecer que primam a uma razão indolente, abissal e gasta (conforme já abordamos em publicações anteriores: SÜSSEKIND, 2014a e 2014b). Sublinhamos que, em seu texto, a Base reforça sua crença na possibilidade de particionar os conhecimentos em áreas e componentes curriculares e encadear linearmente, em função de uma hierarquia constituída por ela mesma, o aprendizado de forma articulada e progressiva (SÜSSEKIND; PELLEGRINI, 2016). É assim abissalizadora de conhecimentos glocais - porque soprados para fora dos sujeitos e das relações tornam-se estruturas sem acontecimentos, ou cidades abandonadas. Entretanto, seu direito fundante, ao ser colado em uma base escriturística, preguiçosa e prepotente, passa a ser caça e caçador de si mesmo, já que em tal proposta a educação existe somente dentro das categorias das áreas que parece objetivar apenas "uma vasta semialfabetização, centrada na leitura" (CERTEAU, 1994, p. 262) do tipo escriturística, para qual "ler é peregrinar por um sistema imposto (o do texto, análogo a ordem construída de uma cidade ou supermercado)" (p. 264).

É nesse sentido que a discussão proposta por Santos (2013, p. 13) a respeito dos direitos humanos foi enredada à problematização do direito à educação como direito a aprender o que está na Base. Se, por um lado, os direitos humanos se tornam símbolo incontestável de dignidade humana, por outro, cada vez mais o discurso sobre os direitos humanos é empregado para justificar sua própria violação. Questões como quais outras lógicas de dignidade humana existem no mundo, se a hegemonia dos direitos humanos na contemporaneidade seria uma vitória ou uma derrota histórica, ou até mesmo se seria possível produzir usos contra-hegemônicos de tal entendimento dos direitos humanos que não protegem grande parte da população mundial, são dúvidas pertinentes. Sobretudo depois de assistirmos, em prol da educação para todos, a ampliação das desigualdades nos sistemas educacionais dos EUA, Suécia (EDLING, 2014) e África do Sul após reformas de unificação curricular vinculadas à padronização nas testagens bastante similares (SÜSSEKIND, 2014a).

Como consta nos princípios da Base Curricular Comum Nacional, é direito do praticante da educação básica o respeito e acolhimento de seus saberes, assim como a apropriação dos saberes necessários à sua dignidade. Nesse sentido, a Base diz assegurar aos estudantxs a garantia de produção de conhecimentos que estejam de acordo com as diversas gramáticas de dignidade possíveis. Entretanto, ao assumir a concepção de comum como igual, a perspectiva de unificação 
curricular abissaliza outras formas de compreensão de mundo que entendem o temos em comum é nossa condição ontológica de produção de diferença. O comum é a diferença, nessa perspectiva.

Entendemos assim o comum como necessariamente uma comunidade de diferentes. Dife-renças podem ser valorizadas (SANTOS, 2010), inclusive pelos currículos, oportunizadas como tessituras de alteridade. Contudo, numa perspectiva de unificação curricular, os discursos sobre a diferença se sobrepõem à possibilidade de uma prática com a diferença, des-valorizadando e des-reconhecendo toda a inventividade dos praticantes dos cotidianos (SÜSSEKIND, 2014). Assim, tenta apagar a diferença ao desconsiderá-la e torná-la mesmidade (SANTOS, 2010), gerando desigualdade, exclusão, desvio, in-adequação, in-disciplina, in-capacidade, invisibilidade e inexistência.

\section{Deixa a tristeza pra lá, vem comer, me jantar ${ }^{8}$}

Se não existe pecado ao sul do Equador ${ }^{9}$ é porque nos reconhecemos na opressão, no assalto, nos tsunamis de políticas e economicismos globalizantes, nas margens, gazeteiramente, cafuzamente, malandramente. Assim, em situações de relações Suleadas para diferença, como se faz nas práticas docentes ecológicas, conversas complicadas em que aprendemosensinamos, os conhecimentos criados tendem a ser de valorização da diferença quando não buscam consensos nem juízo, mas (re)conhecimento. São reconhecimentos, e "o reconhecimento muitas vezes nos obriga a suspender o juízo para podermos apreender o outro" (BUTLER, 2015, p. 63), seja nas escolas, universidades ou nas pesquisas com escolas.

Nos colocamos ao Sul pela denúncia de que o direito à educação se faz como uma palavra soprada para longe do corpo (DERRIDA, 2011, p. 258), numa base, e por isso oferece-se como espetáculo e tem a potência de significação pelo outro roubada. A Base é fatiada pela reificação do direito à educação em conteúdos: os objetivos e sequências de aprendizagem. Contudo, a Base, abissalizadora da diferença, da pluralidade e da imprevisibilidade cotidiana, que não se sustenta senão também nas epistemologias do Norte (SÜSSEKIND; PELLEGRINI, 2016), acaba sendo devorada pelo Sul.

Foi porque nunca tivemos gramáticas, nem coleções de velhos vegetais. $E$ nunca soubemos o que era urbano, suburbano, fronteiriço e continental. Preguiçosos no mapa-múndi do Brasil.

Contra a realidade social, vestida e opressora, cadastrada por Freud - a realidade sem complexos, sem loucura, sem prostituições e sem penitenciárias do matriarcado de Pindorama. (ANDRADE, 1928)

\footnotetext{
${ }^{8}$ Não Existe Pecado Ao Sul do Equador. Compositor: Chico Buarque - Ruy Guerra. 1972 @ by Cara Nova Editora Musical Ltda.

${ }^{9}$ Não Existe Pecado Ao Sul do Equador. Compositor: Chico Buarque - Ruy Guerra. 1972 @ by Cara Nova Editora Musical Ltda.
} 
NÃO EXISTE PECADO | Maria Luiza Süssekind e Raphael Pellegrini

\section{Referências}

ALVES, N. Sobre movimentos das pesquisas nos/dos/ com os cotidianos. In: OLIVEIRA, I. B.; ALVES, N. A Pesquisa nos/dos/com os cotidianos das escolas sobre redes de saberes. Rio de Janeiro: DP et Alii, 2008.

ANDRADE, O. Manifesto Antropofágico. 1928. Disponível em: <http://www.ufrgs.br/cdrom/oandrade/oandrade.pdf>. Acesso em: 10 out. 2016.

ANPED. Ofício n. 01/2015/GR: Exposição de Motivos sobre a Base Nacional Comum Curricular. Rio de Janeiro: Anped, 2015. Disponível em: <http://www.anped.org. br/sites/default/files/resources/Of_cio_01_2015_CNE_ BNCC.pdf>. Acesso em: 07 maio 2016.

BRASIL. Constituição (1996). Lei no 9394, de 20 de dezembro de 1996. Diretrizes e Bases da Educação Nacional. Brasília-DF, 1996.

Diretrizes Curriculares Nacionais Gerais da Educação Básica. Brasília, DF: Ministério da Educação, 2013

Plano Nacional de Educação PNE 2014-2024. Brasília: Inep, 2015.

Base Nacional Comum Curricular. Brasília: MEC/SEB. 2015.

MEC. Sobre o Pisa. Disponível em: <http://portal.inep.gov.br/pisa/sobre-o-pisa>. Acesso em: $26 \mathrm{dez}$. 2016a.

BRASIL. Ministério da Educação. Base Nacional Comum Curricular: Proposta Preliminar Segunda Versão Revista. 2016. Disponível em: <http://basenacionalcomum.mec.gov.br/documentos/bncc-2versao.revista. pdf>. Acesso em: 26 dez. 2016b.

BUTLER, J. Relatar a si mesmo. Crítica da violência ética. Belo Horizonte, Ed Autêntica, 2015. Trad. Rogerio Betoni.

CERTEAU, M. A invenção do cotidiano 1: As artes de fazer. Rio de Janeiro: Vozes, 1994.

DELEUZE, G; GUATTARI, F. Mil platôs: capitalismo e esquizofrenia 2. vol.1. São Paulo: Editora 34, 2012.

DELEUZE, G.; PARNET, C. Transcrição da entrevista o Abecedário de Deleuze. 1994. Disponível em: <http:// stoa.usp.br/prodsubjeduc/files/262/1015/Abecedario+G.+Deleuze.pdf>. Acesso em: 26 dez. 2016.

DERRIDA, J. A escritura e a diferença. São Paulo: Perspectiva, 2011.
EDLING, S. O conceito de pluralidade no currículo nacional sueco: estudando a importância de livros didáticos teóricos de formação de professores para interpretar e constatar as diferentes facetas de violência no trabalho diário de professores. Revista E-curriculum, Pucsp, v. 12, n. 3, p.1634-1668, dez. 2014.

EZPELETA, J.; ROCKWELL, E. Pesquisa Participante. São Paulo: Cortez, 1989.

FOUCAULT, M. A Verdade e as Formas Jurídicas. Rio de Janeiro: Nau Editora, 2013.

GIARD, L. História de uma pesquisa. In: CERTEAU, M. de. A invenção do cotidiano: 1 , Artes de fazer. Petrópolis: Vozes, 1994.

LÉVI, Pierre. O que é o virtual? São Paulo: Editora 34, 1996. $160 \mathrm{p}$.

LOPES, A. C. Por um currículo sem fundamentos. Linhas Críticas, Brasília, v. 21, n. 45, p.445-466, ago. 2015.

MACEDO, E. Base nacional comum para currículos: direitos de aprendizagem e desenvolvimento para quem? Educ. Soc., Campinas, v. 36, no. 133, p. 891-908, out.dez., 2015

MILLER, J. Response to Ruben A. Gaztambide-Fernandez: Communities Without Consensus IN: Curriculum studies handbook-the next moment / ORg Erik Malewski. New York, N.Y. : Routledge, 2010, 566 p. 94-100.

MOREIRA, A. F. B. O currículo como política cultural e a formação docente. In: SILVA, T. T.; MOREIRA, A. F. B. (Org). Territórios contestados: O currículo e os novos mapas culturais. Petrópolis: Vozes, 1995.

OESTE, Q. N. S. L. Rap Global. Rio de Janeiro: Aeroplano, 2010.

OLIVEIRA, I.B. O Currículo como criação cotidiana. Petrópolis: DP et Alli, 2012.

PARASKEVA, J. Conflicts in Curriculum Theory: Challenging Hegemonic Epistemologies. New York: Palgrave/MacMillan, 2011.

PINAR, W. F. A equivocada educação do publico nos Estados Unidos, In: GARCIA, R. L. e MOREIRA, A. F. B. (orgs). Currículo na Contemporaneidade: incertezas e desafios. São Paulo: Cortez, 2008.

PINAR, W. F. Multiculturalismo Malicioso. Currículo Sem Fronteiras, [s.I.], v. 9, n. 2, p.149-168, dez. 2009.

PINAR, W. F. What is curriculum theory? New Jersey, Lawrence Erlbaum, 2005/2012. 
NÃO EXISTE PECADO | Maria Luiza Süssekind e Raphael Pellegrini

PINAR, W. F.; MILLER, J.. Communities of Dissensus/ Engaged Generosity. 2014. Disponível em: <http://blogs. arcadia.edu/educadian/2014/03/25/2014-american-association-for-the-advancement-of-curriculum-studies-aaacs-conference/>. Acesso em: 07 dez. 2016.

PRICE, T. A. Comum para quem? Revista E-curriculum, Pucsp, v. 12, n. 3, p.1614-1633, dez. 2014.

SANTOS, B.S. Por uma concepção multicultural de direitos humanos. In: SANTOS, B.S. (Org.). Reconhecer para libertar: os caminhos do cosmopolitismo multicultural. Rio de Janeiro: Civilização Brasileira, 2003. p. 427462.

SANTOS, B. S. A filosofia à venda, a douta ignorância e a aposta de Pascal. Revista Crítica de Ciências Sociais, Coimbra, v. 1, n. 80, p.11-43, mar. 2008. Disponível em: <http://www.ces.uc.pt/bss/documentos/A_filosofia_a_venda_RCCS80_Marco2008.pdf>. Acesso em: 07 dez 2016

SANTOS, B. S. Para além do pensamento abissal: das linhas globais a uma ecologia de saberes. In: SANTOS, B. S.; MENESES, M. P. (Org). Epistemologias do Sul. São Paulo: Cortez, 2010. p. 31-83.
SANTOS, B. S. Se deus fosse um ativista dos direitos humanos. Coimbra: Ed. Almedina, 2013.

SOFOCLES. Édipo rei. Porto Alegre: L\&pm, 1998.

SÜSSEKIND; M. L. As (im)possibilidades de uma Base Comum Nacional. Revista E-curriculum, São Paulo, v.12, n.03, p.1512-1529, out./dez.2014a. Disponível em: <http://revistas.pucsp.br/index.php/curriculum/article/ view/21667/15917> Acesso em: 4 fev. 2015.

As artes de pesquisar nosdoscom os cotidianos. In: OLIVEIRA, I. B.; GARCIA, A. (Org.). Aventuras do conhecimento: utopias vivenciadas nas pesquisas em educação. Petrópolis, RJ: De Petrus; Rio de Janeiro, RJ : FAPERJ, 2014b.

SÜSSEKIND, M. L.; PELLEGRINI, R. "A escrita nunca escrita" ou por que (re)afirmamos nossa contrariedade à Base Comum. In: FRANGELLA, R. C. P. (Org.). Currículo, formação e avaliação: redes de pesquisas em negociação. Curitiba: CRV, 2016.

PINAR, W. F. Quem é William F. Pinar? Petrópolis: DPetAlii, 2014. 